Jaris Mujica, “Armas pequeñas en el crimen urbano. Delitos, acceso y mercados ilegales de armas de fuego en Lima", $1^{a}$ Edición. Lima, Rerú: CLACSO y CISEPA, 2012. 80 páginas. Documento Electrónico recuperado de: http://biblioteca. clacso.edu.ar/gsdl/collect/clacso/index/assoc/ D5807.dir/mujica.pdf

\title{
Armas pequeñas en el crimen urbano. Delitos, acceso y mercados ilegales de armas de fuego en Lima
}

Este artículo, a través de su investigación nos acerca al tema del uso de las armas pequeñas en el crimen urbano en el Perú entre los años 2006 y 2010, los índices de los homicidios, delitos cometidos, y la forma de accesar a los distintos tipos de armas; por medio de los mercados formales e informales, que a su vez forman el mercado negro en este país. Esta sinopsis nos habla acerca de la investigación del autor realizó con la colaboración del Programa Regional de Becas del Congreso Latinoamericano de Ciencias Sociales (CLACSO).

$>$ Se calcula que hay 875 millones de armas de fuego pequeñas y ligeras circulando en el mundo y el $74 \%$ están en manos de civiles (IANSA, 2006: $3 \cdot 4)^{1}$.

$>$ De cada 1,000 muertes por armas de fuego, solo 250 ocurren en guerras o conflictos, los restantes son homicidios (56\%), suicidios (14\%) y muertes accidentales (5\%).

$>$ Alrededor de 8 millones de nuevas armas pequeñas y ligeras se fabrican cada año aunque sigue siendo más importante el comercio de armas de segunda mano. (Gillis, 2009; IANSA, 2006; Jackson 2005)².

$>$ América Latina tiene un cuadro de homicidios por armas de fuego en ausencia de conflictos armados (Saenz, 2007).

La investigación se rige en: a) Tipos de delitos cometidos con armas pequeñas, b) Las formas de acceso a las armas para el crimen urbano, y c) El mercado informal de armas pequeñas en Lima (entre el año 2006 y el año 2010).

Con el fin del conflicto armado interno en el Perú (1980-2000), se ha observado una expansión de la delincuencia común y casos aislados de crimen organizado. Esto se manifiesta en la sensación de temor e inseguridad de la ciudadanía. En el año 2010, por ejemplo, Perú tenía el porcentaje más alto de América en términos de percepción de inseguridad (53.8\%). Este fenómeno ha incidido en un aumento considerable de armas de fuego registradas, vendidas e incautadas, así como en el crecimiento en el volumen del comercio de armas y la venta al menudeo.

1 International action network on small arms.

2 Costa y Romero. 


\section{WEB}

En el Perú hay más armas, más denuncias por robos con armas de fuego, asaltos en bancos con armas de fuego y secuestros, pero no hay un aumento proporcional de disparos y muertes por armas de fuego. La explicación que se ofrece tiene dos enfoques: a) la transformación y el aumento del comercio formal de armas y la importación de armamento barato; y b) la precariedad de los mercados informales e ilegales de armas de fuego, la antigüedad y el alto costo de las armas ilegales, la escases de ellas en el mercado y la irrupción de las réplicas.

El origen de las armas ilegales del mercado informal tiene diversas fuentes. Pero vale resaltar que ni la importación ni el tráfico y el contrabando internacional, ni el narcotráfico son las fuentes principales. Éstas tienen su origen en: a) las que circulan como perdidas, robadas o vendidas al mercado informal de los civiles y de la seguridad privada; b) las que circulan en el mercado informal de venta individual de las armas cuya licencia no han sido renovadas; y c) las que recirculan en las requisas de la policía.

Por lo que se puede concluir que las armas provienen de la única fuente que combina: a) el acceso al arma larga en términos de accesibilidad y asequibilidad, b) el acceso a la munición para estas armas, y c) el entrenamiento básico: miembros en retiro, de baja o en servicio de las Fuerzas Armadas o la Policía. Este argumento se refuerza cuando se constata que las armas largas utilizadas en el crimen urbano son sustancialmente las mismas que las que poseen las Fuerzas Armadas y la Policía: AK47, HK-G3, FAL, y no hay un arsenal diferente al oficial, además de que su origen es aparentemente el mismo.

El mercado ilegal de armas de fuego en Lima es un mercado negro (Mujica, 2008; Novak, 1985), pues implica la acumulación de un recurso escaso, peligroso y de difícil acceso. Este mercado negro es producido por una condición particular de la dinámica comercial de las armas: la irregularidad del contrabando y del comercio internacional, la escasez relativa de las armas, los altos precios del mercado formal y el limitado tráfico interno.

Este trabajo investigativo enriquece al lector en la búsqueda por conocer la realidad latinoamericana y específicamente en Lima, sobre el tráfico legal e ilegal de armas y el crecimiento del mercado negro entre los años 2006-2010 en el periodo post conflicto armado.

Sinopsis a cargo de Mariella Guadalupe Vega Gutiérrez Jefa de la Unidad de Acceso a la Información Pública Institucional UAIPI-ANSP 